\title{
Frequency of Thrombocytopenia during Pregnancy \& Its Effect on Pregnancy \& Neonatal Outcome
}

\author{
Dr. Homaira Shahreen (Simi)* \\ Assistant Professor (Obst\&Gynae), Rajshahi Medical college Hospital, Rajshahi, Bangladesh
}

*Corresponding Author: Dr. Homaira Shahreen (Simi), Assistant Professor (Obst\&Gynae), Rajshahi Medical college Hospital, Rajshahi, Bangladesh, Email: homairashahreen@gmail.com

\begin{abstract}
Background: Thrombocytopenia is $2^{\text {nd }}$ most common hematological disorder in pregnancy after anemia, and occur approximately 7-10\% of pregnancy. The physiological thrombocytopenia of pregnancy is mild and has no adverse effects on the mother and fetus. By contrast, a significant thrombocytopenia associated with medical conditions can have serious maternal-fetal consequences and requires specific monitoring and appropriate management.
\end{abstract}

Objective: To find out the Frequency of Thrombocytopenia during Pregnancy \& Its Effect on Pregnancy \& Neonatal Outcome.

Methods: It was a prospective study conducted at Rajshahi Medical college Hospital, Rajshahi, Bangladesh. Pregnant females were taken from OPD and Indoor wards of Department of Obstetrics and Gynecology during January 2019 to December 2019. All women after 28 week of gestation (according to last menstrual period or first trimester fetal ultrasonography) were screened for platelet count. The cause of thrombocytopenia and fetomaternal outcomes in pregnancy with thrombocytopenia was studied.

Results: Among 2750 deliveries, total 100 women were having thrombocytopenia. The commonest etiology was gestational thrombocytopenia 66\%. Maternal complications was Placental abruption 5\%, PPH 9\%, episiotomy hematoma 5\%, C.S. wound hematoma 1\%,whole blood \&PRBC transfusion 26\%, platelet transfusion 23\%, FFP transfusion $10 \%$ and ICU admission 7\% were noted. Fetal complications wereAPGAR score at $1 \mathrm{~min}$. (<7) 59\%, APGAR score at $5 \mathrm{~min}$. (<7) 43\%, IUFD 2\%, NICU admission 21\%, and neonatal thrombocytopenia 1\%, IUGR 4\%.

Conclusion: Fetomaternal complications with thrombocytopenia depend primarily on the disease causing it. Gestational thrombocytopenia is most common cause of thrombocytopenia, preeclampsia, HELLP syndrome, malaria, ITP and dengue were other causes of thrombocytopenia in pregnant. Patients with Gestational thrombocytopenia have better maternal and perinatal outcomes as compared to preeclampsia and HELLP syndrome.

Keywords: Frequency, Thrombocytopenia, Pregnancy, Outcome.

\section{INTRODUCTION}

Thrombocytopenia is $2^{\text {nd }}$ most common hematological disorder in pregnancy after anemia, and occur approximately $7-10 \%$ of pregnancy. There is a physiological decrease in platelet count during normal pregnancy due to haemodilution, increased consumption in peripheral tissue and increased aggregation (higher levels of thromboxane A2).

The physiological thrombocytopenia of pregnancy is mild and has no adverse effects on the mother and fetus. By contrast, a significant thrombocytopenia associated with medical conditions can have serious maternal-fetal consequences and requires specific monitoring and appropriate management. Thrombocytopenia is a disorder of the platelets, define as platelet count less than $150 \times 109 / \mathrm{L}$ $[1,2]$. Thrombocytopenia affects $6-10 \%$ of all pregnant women.[3] Most studies report a reduction in platelet count about $10 \%$ lower than the pre-pregnant values. It may be a diagnostic and management problem, and has many causes, some of which are specific to pregnancy.[4] Although most cases of thrombocytopenia in pregnancy are mild, and have no adverse outcome for either mother or baby, occasionally a low platelet count may be part of a more complex disorder with significant morbidity and 
may be life threatening uremic syndrome, and immune thrombocytopenia (ITP) may relapse or be first detected during pregnancy.[5]Normal platelet count in blood is $150-450 \times 109 / \mathrm{L}$. It is the second most common hematological disorder after anemia as the most common hematological abnormality in pregnancy [6]. Thrombocytopenia develops in $5 \%$ to $10 \%$ of women during pregnancy or in immediate postpartum period [4].Overall, about $75 \%$ of cases are due to gestational thrombocytopenia; 15-20\% secondary to hypertensive disorders; $3-$ $4 \%$ due to an immune process, and the remaining 1-2\% made up of rare constitutional thrombocytopenia's, infections and malignancies.[8]We carried out the present study to see the Frequency of thrombocytopenia during pregnancy, its cause and effect on fetomaternal outcome.

\section{MAterials ANd Methods}

It was a Frequency study conducted at Rajshahi Medical college Hospital, Rajshahi, Bangladesh. Pregnant females were taken from OPD and Indoor wards of Department of Obstetrics and Gynecology during January 2019 to December 2019. All women after 28 week of gestation (according to last menstrual period or first trimester fetal ultrasonography) were screened for platelet count. Platelet count of $1,00,000$ to $1,50,000 / \mu \mathrm{L}, 50,000$ to $1,00,000 / \mu \mathrm{L}$ \&were classified as mild, moderate and severe thrombocytopenia respectively. Informed consent was taken. Detailed menstrual, obstetric history was taken. Etiologies of thrombocytopenia were evaluated according to proforma. Systolic \& diastolic blood pressure was taken. Investigations were sent in form of complete blood hemogram, detection of malaria by antigen detection (rapid diagnostic test or RDTs) and/or peripheral blood smear, urine for random sugar and urine for albumin. Blood pressure $>160 / 110 \mathrm{~mm}$ of $\mathrm{Hg}$ with urine albumin $>=+1$ for $>$ two readings 24 hours apart were defined as having severe preeclampsia. Other etiologies were diagnosed by liver function test, coagulation profile, dengue $\operatorname{IgG}$ and IgM antibody titers. Antiphospholipid antibodies were tested after ruling out all other etiologies. Women already diagnosed having immune causes of thrombocytopenia were also evaluated. Women with moderate thrombocytopenia without any other cause were classified as having gestational thrombocytopenia. The following characteristics were compared: intrapartum and post-partum complications such as placental abruption, and severe postpartum bleeding. Women who needed blood transfusion were also studied. Fetal outcomes were compared with regard to birth weight, birth asphyxia, Apgar scores at 1 and 5 minutes, admission to the Neonatal Intensive Care Unit (NICU), neonatal thrombocytopenia (platelet count of $<150 \times$ 109/L), and stillbirth. Newborns weighing < 2500 grams were classified as 'low birth weight'. Platelet counts of all newborns were observed in the first 48 hours postpartum.

\subsection{Inclusion Criteria}

- All pregnant women who have diagnosed thrombocytopenia and newly diagnosed thrombocytopenia.

- All pregnant women agree for complete blood count check-up.

- Women willing to give consent for participate in the study.

\subsection{Methodology}

It was a prospective 6 month study of pregnancy with thrombocytopenia. The cause of thrombocytopenia and fetomaternal outcomes in pregnancy with thrombocytopenia was studied.

- Pregnant women have thrombocytopenia was selected.

- Informed consent of the patient was taken prior to study.

- To control inter-observer variability same method of sample collection, same complete blood cell counter machine and same reagents, almost same antenatal prescription used and all data was observed by the investigator herself.

- Baseline investigations like complete haemogram, blood group and $\mathrm{Rh}$ typing, urine analysis, VDRL, HBsAg and HIV serology were carried out in all patients.

\section{RESUltS}

Among 2750 deliveries, total 100 women were having thrombocytopenia. Thus the Frequency was found to be $3.63 \%$ Table 1 shows. As shown in table 2: most common cause of thrombocytopenia in pregnancy is gestational thrombocytopenia (66\%), hypertensive disorder of pregnancy (preeclampsia, eclampsia) is second most common cause ( $23 \%), 1 \%$ due to ITP, $6 \%$ due to malaria and $4 \%$ due to dengue. Table 3 shows that PPH is the most common maternal complication 9\% followed by abruption 5\%, patient having episiotomy 
hematoma are $5 \%, 1 \%$ cases having C.S. wound hematoma, $26 \%$ patients were transfused whole blood or PRBC, 23\% were transfused platelets and $10 \%$ were transfused FFP. 7\% patients were required ICU admission. Table 4 shows APGAR score $<7 / 10$ at $1 \mathrm{~min}$ and $5 \mathrm{~min}$ are 58 $\%$ and $43 \%$ respectively. $2 \%$ are IUFD, $1 \%$ is $\mathrm{SB}, 21 \%$ newborn is admitted in NICU, neonatal thrombocytopenia is reported in $1 \%$ cases. $4 \%$ newborn is IUGR due to HDP and nutritional deficiency. Newborn with intracranial hemorrhage due to thrombocytopenia were not reported in present study.

Table1: Frequency of thrombocytopenia

\begin{tabular}{|l|ll|l|}
\hline $\begin{array}{l}\text { Total } \\
\text { deliveries }\end{array}$ & $\begin{array}{l}\text { Cases of } \\
\text { thrombocytopenia }\end{array}$ & Frequency \\
\hline 2750 & 100 & $3.63 \%$ \\
\hline
\end{tabular}

Table2: Distribution of cases according to causes of thrombocytopenia

\begin{tabular}{|l|l|l|}
\hline CAUSE & $\begin{array}{l}\text { No. of } \\
\text { patients }\end{array}$ & Percentage \\
\hline $\begin{array}{l}\text { Gestational } \\
\text { thrombocytopenia }\end{array}$ & 66 & 66 \\
\hline $\begin{array}{l}\text { Hypertensive disorder } \\
\text { of pregnany }\end{array}$ & 23 & 23 \\
\hline ITP & 1 & 1 \\
\hline Malaria & 6 & 6 \\
\hline Dengue & 4 & 4 \\
\hline
\end{tabular}

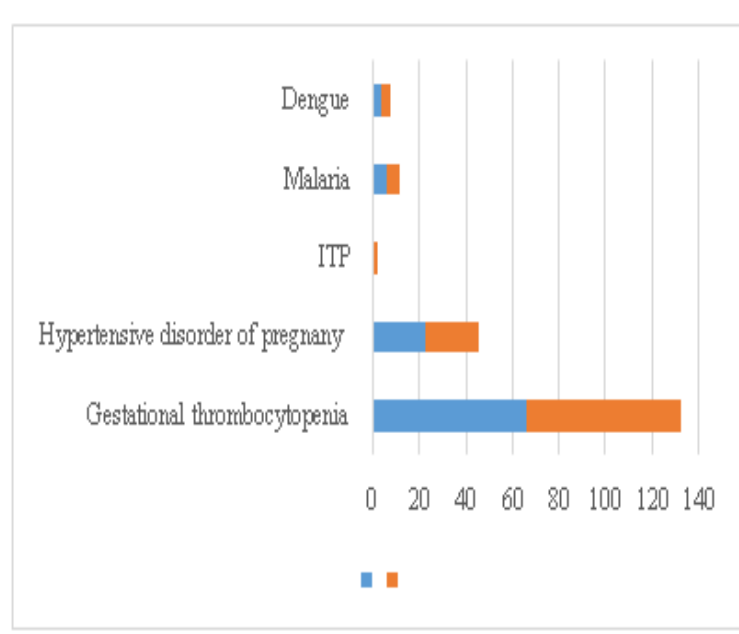

Figure1: Distribution of cases according to causes of thrombocytopenia

Table3: Distribution of cases according to maternal outcome

\begin{tabular}{|l|c|c|}
\hline Maternal outcome & $\begin{array}{c}\text { No. of } \\
\text { patients }\end{array}$ & Percentage \\
\hline Abruption & 5 & $5 \%$ \\
\hline PPH & 9 & $9 \%$ \\
\hline $\begin{array}{l}\text { Episiotomy } \\
\text { hematoma }\end{array}$ & 5 & $5 \%$ \\
\hline $\begin{array}{l}\text { C.S. wound } \\
\text { hematoma }\end{array}$ & 1 & $1 \%$ \\
\hline
\end{tabular}

ARC Journal of Gynecology and Obstetrics

\begin{tabular}{|l|c|c|}
\hline $\begin{array}{l}\text { Whole blood / PRBC } \\
\text { transfusion }\end{array}$ & 26 & $26 \%$ \\
\hline Platelet transfusion & 23 & $23 \%$ \\
\hline FFP transfusion & 10 & $10 \%$ \\
\hline ICU admission & 7 & $7 \%$ \\
\hline
\end{tabular}

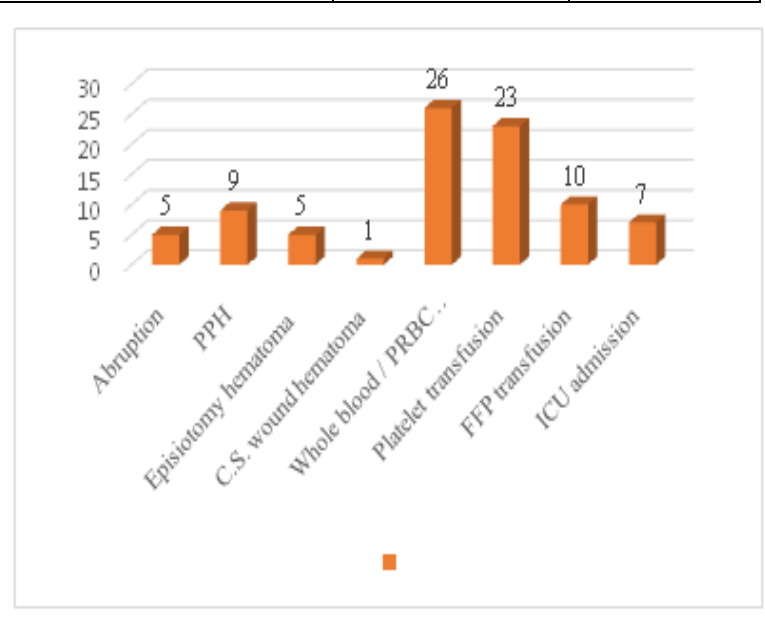

Figure2: Distribution of cases according to maternal outcome

Table4: Distribution of cases according to fetal outcome

\begin{tabular}{|l|l|l|}
\hline Fetal outcome & $\begin{array}{l}\text { No. of } \\
\text { patients }\end{array}$ & Percentage \\
\hline $\begin{array}{l}\text { Apgar score at } 1 \\
\text { min }(<7)\end{array}$ & 59 & $59 \%$ \\
\hline $\begin{array}{l}\text { Apgar score at } 5 \\
\text { min }(<7)\end{array}$ & 43 & $43 \%$ \\
\hline IUFD & 2 & $2 \%$ \\
\hline SB & 0 & $0 \%$ \\
\hline NICU admission & 21 & $21 \%$ \\
\hline $\begin{array}{l}\text { Neonatal } \\
\text { thrombocytopenia }\end{array}$ & 1 & $1 \%$ \\
\hline IUGR & 4 & $4 \%$ \\
\hline ICH & 0 & $0 \%$ \\
\hline
\end{tabular}

\section{DISCUSSION}

Frequency of thrombocytopenia in our study is $3.63 \%$ similar to a study by Shashikalakaranth et al. [9], $2.25 \%$. In another study Varghese S et al.[10], Frequency is $4.2 \%$, comparable with present study. However, the Frequency of this study was lower than in studies by Asrie et al. [11], Arora et al.[12] P Dwivedi et al. [13] and Singh S et al. [14], the Frequency were $8.8 \%$, $9.4 \%, 8.17 \%$ and $8.8 \%$ respectively. Maternal complication were mainly abruption (5\%), $\mathrm{PPH}$ (9\%). In a study Arora et al. [12] (2017), $6.6 \%$ mothers complicating by abruption. Which is similar to present study. In a study Singh S et al. [14], $9.8 \%$ cases face $\mathrm{PPH}$, which is comparable to present study, but in another studies such as Arora et al. [11], Vesnaet al.[15] and ShashikalaKaranth et al. [9] the PPH is 4.3 $\%, 2 \%$ and $4.3 \%$ respectively which is lower than present study. This is because of most of 
patients having anemia, HDP, unbooked and different sociodemographic conditions. These complications were due to impaired haemostasis and ongoing bleed. Other maternal complications includes caesarean wound hematoma (1\%), episiotomy site hematoma (5\%), these are less than a study Arora et al. [12] $3.6 \%$, in studies conducted by ShashikalaKaranthet al. [9] 0\%, Varghese S et al. [6] 0\% and P Dwivedi et al. [13] 0\%. This is because of more patient load at this tertiary center due to most of patient refered from wide peripheral area where lack of speciality services. There were no maternal deaths in our study as compared to Shashikalakaranth et al. [9], Nisha $\mathrm{S}$ et al. and Usha et al. where they reported $2 \%$, $5.26 \%$ and $4.37 \%$ maternal mortality respectively. This is due to strict surveillance and management. The present study shows thrombocytopenia is not directly related to maternal outcome, there are also other factors which influence the maternal outcome like anemia, preeclampsia, sepsis etc. thrombocytopenia is an additional factor and not independent factor. In our study $59 \%$ newborn were having APGAR score $<7$ at $1 \mathrm{~min}$. some of them get improved in 5 minutes. So $43 \%$ were having APGAR score $<7$ at $5 \mathrm{~min}$. Whereas Shashikalakaranth et al. [9] observed APGAR $29.78 \%<7$ at $1 \mathrm{~min}$. and $8.5 \%$ having APGAR $<7$ at 5 min. which similar to present study but Arora et al. [12] observed $9.45 \%$ and $6.57 \%$ newborn APGAR $<7$ at $1 \mathrm{~min}$ and $5 \mathrm{~min}$ respectively. This difference due to high cases of hypertensive disorder of pregnancy which leads to more newborn with IUGR and low birth weight in present study. In our study IUFD and Still Birth newborn were $2 \%$ \& $0 \%$ respectively. $1 \%$ newborn having neonatal thrombocytopenia, Abruption and hypertensive disorder of pregnancy were major factor contributing to this worse fetal outcome. About $1 \%$ (1case) newborn was neonatal thrombocytopenia. In studies conducted by Wang et al. [16] and Vesna et al. [15]neonatal thrombocytopenia $7.7 \%$ and $8 \%$ respectively. In another study by Shashikalakaranth et al. [9] the neonatal thrombocytopenia was $18.45 \%$, which is much more than present study. This is shows that mother having ITP and hypertensive disorder of pregnancy with severe thrombocytopenia may cause neonatal thrombocytopenia. Otherwise maternal thrombocytopenia is not a predictive factor for neonatal thrombocytopenia .The Frequency of IUGR is $4 \%$. In study conducted by Vesnaet al. [12] and M Parnas et al. [17] the IUGR were 8\% and $8.5 \%$ respectively. These results were consistent with result of present study. In another study by Shashikalakaranth et al. [9] the IUGR newborns were $46.6 \%$. Their study result was much higher than most of studies as discuss in table below, because of most of pregnant women of their study group are hypertensive disorder of pregnancy. But in our study $66 \%$ cases of gestational thrombocytopenia.

\section{CONClusion}

Gestational thrombocytopenia is the commonest cause of thrombocytopenia may not be related to adverse pregnancy outcome thus can be treated as benign condition. Gestational thrombocytopenia is associated with better maternal and perinatal outcome as compared to HDP and ITP which expose them to life threatening complication as placental abruption, PPH, Birth Asphyxia, and Still Birth. Thus accurate etiological diagnosis is essential for optimal therapeutic management. A careful examination and simple laboratory test CBC are needed for diagnosis. Clinical assessment is most important factor for evaluating a patient with thrombocytopenia.

\section{REFERENCES}

[1] Richard F and Alexander H. Thrombocytopenia in pregnancy; 2006. www.emedicine.medscape .com/ article.

[2] Saino S, Kekomaki R, Riikonon S, Teramo K. Maternal thrombocytopenia at term: a population based study. ActaobstetGynecol Scand.[2000 sep];79(9);[744-9]

[3] McCrae KR. Thrombocytopenia in Pregnancy. In: Michelson AD, ed. Platelets. New York, NY: Elsevier. 2006: 925-933.

[4] Boehlen F., Hohlfeld H., Extermann P., Perneger T. \& de Moerloose P. Platelet count at term pregnancy: a reappraisal of the threshold. Obstetrics and Gynecology. 2000; 95, 30.

[5] Boehlen F, Hohlfeld P, Extermann P, Perneger TV, de Moerloose Platelet count at term pregnancy: a reappraisal of the threshold. Obstet Gynecol. 2000; 95(1);29-33

[6] Cunningham FG, Gant NF, Leveno KJ, et al. Hematological disorders. Williams obstetrics, 21st ed. McGraw-Hill, New York 2001, 13071338.

[7] Abdul Rahim Gari-Bai, Fachartz (Hematology) Thrombocytopenia during Pregnancy AR GariBai, Thrombocytopenia during Pregnancy. 1998; 18(2): 135-139.

[8] Burrows R.F. \& Kelton J.G. Thrombocytopenia at delivery: a prospective survey of 6715 deliveries. American Journal of Obstetrics and Gynecology. 1990; 162: 732-734. 
[9] Shashikalakaranth, Shruthi K. Frequency of thrombocytopenia in parturient: Experience in tertiary care center, Indian journal of obstetrics and Gynecology Research, January-March. 2018; 5(1):98-103.

[10] Varghese S, Kour G, Dhar T. Thrombocytopenia in pregnancy in a tertiary care hospital: a retrospective study. Int $\mathbf{J}$ ReprodContraceptObstetGynecol. 2016; 5:1532-5.

[11] FikirAsrie, BamlakuEnawgaw, ZegeyeGetaneh; Frequency of thrombocytopenia among pregnant women attending antenatal care service; Journal of Blood Medicine. 2017:8 61-66.

[12] Arora M, Goyal L, Khutan H. Frequency of Thrombocytopenia during Pregnancy \&Its Effect on Pregnancy \& Neonatal Outcome. Ann. Int. Med. Den. Res.2017;3(2):ME04ME06

[13] Dwivedi P, Puri M, Nigam A, Agarwal K. Fetomaternal outcome in pregnancy with severe thrombocytopenia; European Review for medical and pharmacological sciences. 2012; 16:15631566.
[14] Centers for Disease Control Prevention. National Center for Injury Prevention and Control; Division of Unintentional Injury Prevention. Report to Congress on Traumatic Brain Injury in the United States: Epidemiology and Rehabilitation.

[15] Elveđi-Gašparović $\mathrm{V}, \quad$ Beljan P, GverićAhmetašević S, Schuster S, Škrablin S. Fetal maternal complications and their association with gestational thrombocytopenia. Ginekologiapolska. 2016; 87(6) : 454-9.

[16] Wang X, Xu Y, Luo W, Feng H, Luo Y, Wang Y, Liao H. Thrombocytopenia in pregnancy with different diagnoses: Differential clinical features, treatments, and outcomes. Medicine. 2017 Jul; 96(29).

[17] Parnas M, Sheiner E, Shoham-Vardi I, Burstein E, Yermiahu T, Levi I, Holcberg G, Yerushalmi R. Moderate to severe thrombocytopenia during pregnancy. European Journal of Obstetrics \& Gynecology and reproductive biology. 2006 Sep 1; 128(1-2):163-8.

Citation: Dr. Homaira Shahreen (Simi), Frequency of Thrombocytopenia during Pregnancy \& Its Effect on Pregnancy \& Neonatal Outcome.ARC Journal of Gynecology and Obstetrics. 2020; 5(1):21-25. DOI: doi.Org/ 10.20431/2456-0561.0501004.

Copyright: (C) 2020 Authors. This is an open-access article distributed under the terms of the Creative Commons Attribution License, which permits unrestricted use, distribution, and reproduction in any medium, provided the original author and source are credited. 